\title{
Rapid enzyme-linked immunosorbent assay (ELISA) for Aspergillus fumigatus antibodies
}

\author{
MD RICHARDSON, JUDITH M STUBBINS, DW WARNOCK \\ From the Department of Microbiology, Bristol Royal Infirmary, Bristol BS2 $8 \mathrm{HW}$
}

SUMMARY A rapid enzyme-linked immunosorbent assay (ELISA) where component incubation periods were shortened to one hour, was compared with agar gel double diffusion (AGDD) and a standard ELISA procedure for detecting antibodies to Aspergillus fumigatus in 28 asthmatic patients with suspected allergic aspergillosis. Using two $A$ fumigatus antigens the rapid ELISA compared well with AGDD and the standard ELISA method. Eleven sera that reacted with both antigens in AGDD were all positive against antigen 1 in both forms of ELISA, but two failed to react with antigen 2 in the standard ELISA and three failed to react with this antigen in the rapid method. Thirteen AGDD-negative sera were also negative in both forms of ELISA. The rapid ELISA provides a sensitive and reproducible test for routine serological investigation of allergic aspergillosis.

Serological tests are useful in the diagnosis of allergic and mycetomal forms of aspergillosis in immunocompetent patients. The usefulness of these tests in invasive forms of aspergillosis in immunocompromised patients is less well established.

Agar gel double diffusion (AGDD) is the principal serological method used at present. ${ }^{1-4}$ Precipitins to Aspergillus fumigatus can be detected in the serum of almost all patients with the mycetomal form of aspergillosis. In contrast, serum from patients with allergic aspergillosis often has to be concentrated before precipitins can be detected. Other less time-consuming methods that have been evaluated for the rapid detection of $A$ fumigatus antibodies have included counterimmunoelectrophoresis, ${ }^{56}$ passive haemagglutination, ${ }^{7}$ radioimmunoassay $^{89}$ and indirect immunofluorescence. ${ }^{1011}$

Initial investigations have suggested that enzymelinked immunosorbent assay (ELISA) is helpful in the serological diagnosis of different forms of aspergillosis in both immunocompromised and noncompromised patients. ${ }^{12}{ }^{13}$ However, the incubation times used in these investigations amounted to a total test period of about $24 \mathrm{~h}$. This is less than that required for AGDD, but is still too long in certain clinical situations. Although other rapid serological methods have been devised, these often have subjective endpoints and most are less sensitive. In this investigation, we have studied the effect of shortening the component incubation periods in an indirect ELISA for IgG antibodies to $A$ fumigatus to one hour. The results are compared with those obtained with AGDD and with an established long-form ELISA.

\section{Material and methods}

\section{SUBJECTS}

Serum specimens used in this investigation were obtained from 28 asthmatic patients with suspected allergic aspergillosis. These specimens were tested for $A$ fumigatus precipitins on receipt and were then stored at $-20^{\circ} \mathrm{C}$ until required for further tests. None of the specimens had been stored for longer than 12 months when retested.

\section{AGAR GEL DOUBLE DIFFUSION (AGDD)}

Two commercial $A$ fumigatus antigens (Bencard) were used at concentrations of $20 \mathrm{mg} / \mathrm{ml}$. The medium for this test was prepared by dissolving Noble Agar (Difco) at 3\% concentration in $0.85 \%$ saline, cooling to $60^{\circ} \mathrm{C}$ and then adding an equal volume of Mcllvaine's citrate buffer, $\mathrm{pH} \mathbf{7 \cdot 0}$. Glass 
slides were coated to a depth of $1.5 \mathrm{~mm}$ and a template was used to cut a pattern of peripheral antigen wells of $4 \mathrm{~mm}$ diameter arranged $6 \mathrm{~mm}$ (edge to edge) from a $12.5 \mathrm{~mm}$ diameter central serum well. Diffusion was carried out in a moist atmosphere for $48 \mathrm{~h}$. The slides were washed in $2 \%$ saline overnight, dried, stained with $0.5 \%$ Coomassie Brilliant Blue dissolved in methanol: glacial acetic acid: distilled water $(5: 1: 5)$ and then destained in solvent alone. The presence of precipitins lines was recorded.

\section{LONG ELISA}

The indirect ELISA used for the determination of $A$ fumigatus antibodies was based on the method of Voller $e t$ al. ${ }^{14}$ Optimal concentrations of reagents were first determined using chequerboard titrations.

In subsequent tests, each well of a 96 well polyvinyl microtitre plate (No 1-220-29, Dynatech Laboratories) was first coated with $200 \mu$ l of a solution containing $0.4 \mu \mathrm{g}$ of $A$ fumigatus antigen for $3 \mathrm{~h}$ at $37^{\circ} \mathrm{C}$. The diluent used was $0.05 \mathrm{M}$ sodium carbonate buffer, $\mathrm{pH} 9.6$, containing $0.02 \%$ sodium azide. The coated wells were washed three times for 3 min each with PBS-T: $0.01 M$ sodium phosphate buffer, $\mathrm{pH} 7.2 ; 0.14 M$ sodium chloride and $0.05 \%$ (vol/vol) Tween 20 (polyoxyethylene sorbitan monolaurate) (Sigma) dispensed from a Titertek Autodrop (Flow Laboratories).

Patient serum was diluted $1 / 1000$ with PBS-T and duplicate $200 \mu$ l volumes were added to antigencoated wells and incubated for $2 \mathrm{~h}$ at $37^{\circ} \mathrm{C}$. The plates were then washed three times for 3 min each with PBS-T. Heavy-chain specific goat antiserum to human IgG labelled with alkaline phosphatase (Miles Laboratories) was diluted $1 / 2000$ in PBS-T and $200 \mu \mathrm{l}$ was added to each well. The plates were incubated for $18 \mathrm{~h}$ at $4^{\circ} \mathrm{C}$, washed three times for 3 min each with PBS-T and $200 \mu l$ of fresh p-nitrophenyl phosphate $(1 \mathrm{mg} / \mathrm{ml})$, (Sigma 104 phosphatase substrate tablets) in diethanolamine buffer (diethanolamine, $97 \mathrm{ml}$; distilled water, 800 $\mathrm{ml}$; sodium azide, $0.2 \mathrm{~g} ; \mathrm{pH}$ adjusted to 9.8 with $\mathrm{N}$ $\mathrm{HCl}$ and made up to 11 with distilled water) was added. After incubation at $37^{\circ} \mathrm{C}$ for about $30 \mathrm{~min}$, the reaction was stopped by adding $50 \mu$ l of $3 M$ sodium hydroxide to each well.

Absorbance was read at $405 \mathrm{~nm}$ and $650 \mathrm{~nm}$ with a dual wave length MR 580 Microelisa Autoreader (Dynatech Laboratories).

\section{RAPID ELISA}

The method used was similar to the long ELISA for detection of $A$ fumigatus antibodies. Wells of polyvinyl microtitre plates were coated with $200 \mu \mathrm{l}$ of antigen solution consisting of $0.4 \mu \mathrm{g}$ diluted in
$0.05 M$ sodium carbonate buffer, prewarmed to $37^{\circ} \mathrm{C}$. The wells were coated for $1 \mathrm{~h}$ at $37^{\circ} \mathrm{C}$ in a gyratory incubator at $100 \mathrm{rpm}$. The coated wells were washed three times for $3 \mathrm{~min}$ each with PBS-T.

Duplicate $200 \mu \mathrm{l}$ amounts of patients' serum diluted with PBS-T, were added to the coated wells and incubated at $100 \mathrm{rpm}$ for $1 \mathrm{~h}$ at $37^{\circ} \mathrm{C}$. The plates were washed with PBS-T as before. Anti-human IgG labelled with alkaline phosphatase was diluted 1/2000 with PBS-T and $200 \mu$ l added to each well and incubated at $100 \mathrm{rpm}$ for $1 \mathrm{~h}$ at $37^{\circ} \mathrm{C}$. Substrate solution was added to the washed wells and the plate incubated at $100 \mathrm{rpm}$ for about $30 \mathrm{~min}$ at $37^{\circ} \mathrm{C}$. The reaction was then stopped and read as before.

EXPRESSION OF ELISA DATA

The results were expressed as ELISA units-that is, as percentage absorbance of a reference serum dilution studied on the same occasion. ${ }^{15}$ This serum produced numerous precipitin lines in AGDD and had been obtained from a patient with the mycetomal form of aspergillosis.

\section{Results}

DEVELOPMENT OF THE RAPID ELISA FOR A FUMIGATUS ANTIBODIES

The optimal concentrations of the two $A$ fumigatus antigens used in the rapid ELISA was determined by checkerboard titrations of nine AGDD-positive and nine AGDD-negative sera. A concentration of $0.4 \mu \mathrm{g}$ per $200 \mu \mathrm{l}$ of both antigens was found to be optimal.

To determine the optimal dilution of AGDDpositive and -negative sera for the rapid ELISA, serial dilutions were prepared in PBS-T and tests for the presence of $\mathrm{IgG}$ antibodies against $A$ fumigatus performed. The titration curves obtained with the two $A$ fumigatus antigens are presented in Figs. 1 and 2 . It can be seen that good discrimination between the AGDD-positive reference serum and an AGDD-negative serum was obtained at a dilution of $1 / 1000$ for both antigens.

INTERPRETATION OF ELISA DATA

In both forms of ELISA, discrimination between positive and negative sera was achieved by including the positive reference serum and 10 AGDDnegative sera (which had given minimal absorbance in ELISA determinations) in each test run. The mean absorbance of the 10 negative sera was determined (in ELISA units). This value plus two standard deviations was then taken as the lower limit of positiveness for that test run. Thus, patient sera were regarded as positive if the absorbance was greater than the mean plus two standard deviations of the 10 negative sera tested on the same occasion. 


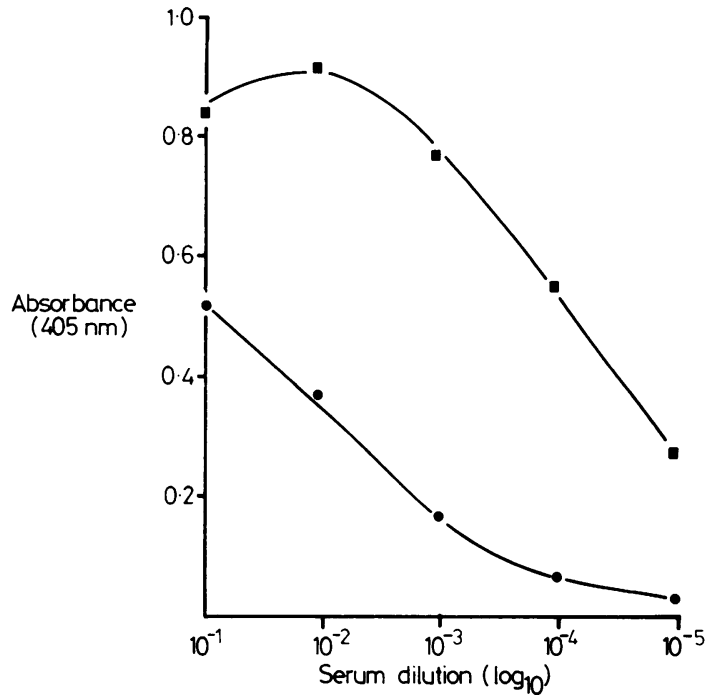

Fig. 1 Curves showing the absorbance values given by the $A G D D$-positive reference serum ( $\square-\square$ ) and an $A G D D$-negative serum $(-\infty)$ when titrated for IgG against $A$ fumigatus antigen 1

COMPARISON OF ELISA AND AGDD

The Table summarises the results obtained with the 28 sera tested for the presence of IgG antibodies against $A$ fumigatus using AGDD and both forms of ELISA. Thirteen AGDD-negative sera were also negative in both forms of ELISA. Eleven sera that reacted with both $A$ fumigatus antigens in AGDD all reacted with antigen 1 in both forms of ELISA, but two failed to react with antigen 2 in the longform ELISA and three failed to react with this antigen in the rapid ELISA.

One of the two sera that reacted with antigen 1 in AGDD, but not with antigen 2 was positive in the long-form ELISA using antigen 1. Both these sera were negative in the rapid ELISA with both antigens. In contrast, two sera reacted with antigen 2 in AGDD but not with antigen 1 , were positive in both

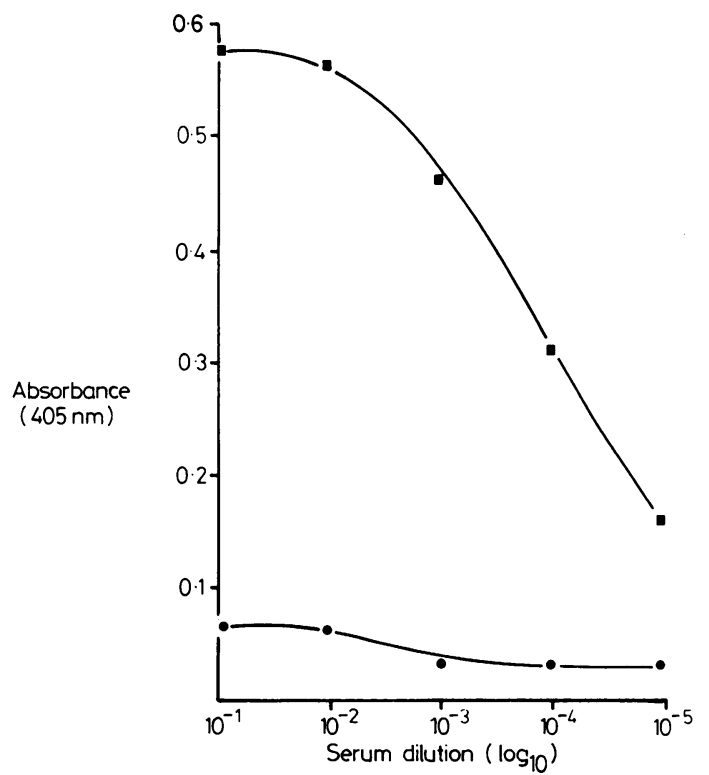

Fig. 2 Curves showing the absorbance values given by the $A G D D$-positive reference serum ( $\square-\square)$ and an $A G D D$-negative serum (-) when titrated for IgG against $A$ fumigatus antigen 2

forms of ELISA with antigen 1. One of these serace was negative in the rapid ELISA with antigen 2.

\section{Discussion}

The findings of this investigation demonstrate that an ELISA method in which incubation times for each stage are reduced to one hour can be used for the rapid detection of $\mathrm{IgG}$ antibodies to $A$ fumigatus, with no loss of sensitivity. The method compares well with the established AGDD method for the detection of $A$ fumigatus precipitins.

No positive results were obtained in either form of ELISA with either $A$ fumigatus antigen in tests with AGDD-negative sera. Negative ELISA results

Correlation between $A G D D$, long and rapid ELISA for IgG antibodies to A fumigatus

\begin{tabular}{|c|c|c|c|c|c|}
\hline \multirow[b]{3}{*}{$A G D D$ reaction } & \multirow[b]{3}{*}{ No of sera } & \multicolumn{4}{|c|}{ Number and (\%) of sera giving positive reactions } \\
\hline & & \multicolumn{2}{|l|}{ Antigen 1} & \multicolumn{2}{|l|}{ Antigen 2} \\
\hline & & Long ELISA & Rapid ELISA & Long ELISA & Rapid ELISA \\
\hline \multirow{4}{*}{$\begin{array}{l}\text { Negative: } \\
\text { antigens } 1 \text { and } 2 \\
\text { Positive: antigen } 1 \text {, } \\
\text { negative: antigen } 2 \\
\text { Negative: antigen 1, } \\
\text { positive: antigen } 2 \\
\text { Positive: } \\
\text { antigens } 1 \text { and } 2\end{array}$} & 13 & 0 & 0 & 0 & 0 \\
\hline & 2 & $1(50)$ & 0 & 0 & $\mathbf{0}$ \\
\hline & 2 & $2(100)$ & $2(100)$ & $2(100)$ & $1(50)$ \\
\hline & 11 & $11(100)$ & $11(100)$ & $9(82)$ & $8(73)$ \\
\hline
\end{tabular}

Number and (\%) of sera giving positive reactions 
were, however, obtained with antigen 2 in both forms of test with a small number of sera that had reacted with this antigen in AGDD. This problem appears to be due to poor binding of antigen 2 to the polyvinyl plates used in our ELISA tests.

Much smaller amounts of antigen and much higher dilutions of antiserum are needed for ELISA than for the established AGDD method for $A$ fumigatus precipitins. Moreover, serum specimens from patients with allergic aspergillosis often have to be concentrated before precipitins can be detected. The concentration of antigen needed for detection of precipitins in AGDD is another critical factor which can be avoided with ELISA.

The method of discrimination between positive and negative sera is one of the most critical aspects of ELISA test standardisation. In this investigation qualitative rather than quantitative results were required-that is, whether a given specimen was positive or negative. The incorporation of a positive reference serum and 10 negative sera as internal standards in each test run permitted good discrimination between negative and positive specimens and also avoided the need for critical standardisation of reaction times. This approach also lessened the need for absolute standardisation of other factors influencing reaction rates.

In conclusion, the rapid ELISA described in this paper is both sensitive and reproducible. It is simple to perform and appears to be a suitable method for routine application in the serological diagnosis of different forms of aspergillosis.

The authors are grateful for the financial support of the Medical Research Committee of the Bristol and Weston Health District (Teaching) during this investigation.

\section{References}

' Coleman RM, Kaufman L. Use of the immunodiffusion test in the serodiagnosis of aspergillosis. Appl Microbiol 1972;23:301-8.
${ }^{2}$ English MP, Henderson AH. Significance and interpretation of laboratory tests in pulmonary aspergillosis. J Clin Pathol 1967;20:832-4.

${ }^{3}$ Longbottom JL, Pepys J. Pulmonary aspergillosis: diagnostic and immunological significance of antigens and C-substance in Aspergillus fumigatus. J Pathol Bacteriol 1964;88:141-51.

4 Schaefer JC, Yu B, Armstrong D. An Aspergillus immunodiffusion test in the early diagnosis of aspergillosis in adult leukemia patients. Am Rev Respir Dis 1976;113:325-9.

${ }^{5}$ Dee TH. Detection of Aspergillus fumigatus serum precipitins by counterimmunoelectrophoresis. J Clin Microbiol 1975;2:482-5.

- Warnock DW. Detection of Aspergillus fumigatus precipitins: a comparison of counter immunoelectrophoresis and double diffusion. J Clin Pathol 1977;30:388-9.

' Gold JWM, Fisher B, Yu B, Chein N, Armstrong D. Diagnosis of invasive aspergillosis by passive haemagglutination assay of antibody. J Infect Dis 1980;142:87-94.

- Bardana EJ Jr, Gerber JD, Craig S, Cianciulli FD. The general and specific humoral immune response to pulmonary aspergillosis. Am Rev Respir Dis 1975;112:799-805.

${ }^{9}$ Marier R, Smith W, Jansen M, Andriole VT. A solid-phase radioimmunoassay for the measurement of antibody to Aspergillus in invasive aspergillosis. $J$ Infect Dis 1979;140:771-9.

${ }^{10}$ Warnock DW. Indirect immunofluorescence test for the detection of Aspergillus fumigatus antibodies. J Clin Pathol 1974;27:911-2.

"Warnock DW, Hann EM. Further evaluation of indirect immunofluorescence methods for detection of antibodies against Aspergillus fumigatus. Sabouraudia 1981;19:49-54.

12 Holmberg K, Berdischewsky M, Young LS. Serologic immunodiagnosis of invasive aspergillosis. J Infect Dis 1980;141:656-64.

${ }^{13}$ Sepulveda R, Longbottom JL, Pepy's J. Enzyme linked immunosorbent assay (ELISA) for IgG and IgE antibodies to protein and polysaccharide antigens of Aspergillus fumigatus. Clin Allergy 1979;9:359-71.

${ }^{14}$ Voller A, Bidwell DE, Bartlett A. Enzyme immunoassays in diagnostic medicine. Bull WHO 1976;53:55-65.

is Kostiala AAI, Kostiala I. Enzyme-linked immunosorbent assay (ELISA) for IgM, IgG and IgA class antibodies against Candida albicans antigens: development and comparison with other methods. Sabouraudia 1981;19:123-34.

Requests for reprints to: Dr MD Richardson, Department of Microbiology, Bristol Royal Infirmary, Bristol BS2 $8 \mathrm{HW}$, England. 